\title{
Effects of Cumin/Maize Intercropping on Crop Productivity, Interspecific Interaction and Water Use Efficiency in the Semi-arid Area of Northwest China
}

\author{
W. L. Zhang ${ }^{1, \uparrow}$, J. R. Shao ${ }^{1, \uparrow}$, L. Shen ${ }^{1}$, T. T. Liu ${ }^{1}$, Tayir Tohti ${ }^{1}$, L. H. Li ${ }^{1} \&$ W. Zhang ${ }^{1}$ \\ ${ }^{1}$ College of Agriculture, Shihezi University, Shihezi, Xinjiang Uygur Autonomous Region, China \\ Correspondence: W. Zhang, College of Agriculture, Shihezi University, Shihezi, Xinjiang 832003, China. E-mail: \\ bluesky2002040@163.com \\ L. H. Li, College of Agriculture, Shihezi University, Shihezi, Xinjiang 832003, China. E-mail: \\ liluhuashiz@163.com \\ Tayir Tohti, College of Agriculture, Shihezi University, Shihezi, Xinjiang 832003, China. E-mail: \\ 2959846313@qq.com
}

Received: June 23, 2021

Accepted: July 27, $2021 \quad$ Online Published: August 15, 2021

doi:10.5539/jas.v13n9p48

URL: https://doi.org/10.5539/jas.v13n9p48

\section{$\dagger$ These authors contributed equally to this work.}

\begin{abstract}
In the semi-arid areas of Xinjiang in China, the agricultural community is facing long-term challenges in improving crop productivity and economic profits. A potential way to improve crop productivity is by intercropping food crops with cash crops. In this two-year field experimental study, we analyzed the advantages of the cumin/maize intercropping system as compared to cultivating them separately from three perspectives: crop growth, interspecific interactions, and water use efficiency. At the experimental site, each cropping systems (i.e., the cumin/maize intercropping system, monocropping cumin system, and monocropping maize system) had three replicates. In the experimental of 2019 and 2020, the three cropping systems showed significant differences in plant height, stem diameter, and leaf area index (LAI). The yields of the cumin/maize intercropping system were both lower than monocropping maize and cumin. However, the cumin/maize intercropping system had a higher land equivalent ratio (LER) than either of the monocropping systems, with a two-year average value of 1.65. Intercropped cumin was less dominant; as shown by aggressivity (Acm; averaging- 0.22 ) and relative crowding coefficient (Rcm; averaging - 3.15). In addition, the cumin/maize intercropping system significantly improved the Water equivalent ratio (WER) as compared to the monocropping systems, with a two-year average value of 1.67. Therefore, the cumin/maize intercropping system is a promising agricultural strategy to improve the utilization rate of agricultural resources and economic benefits in Xinjiang.
\end{abstract}

Keywords: cumin/maize intercropping, crop growth, interspecific interactions, water use efficiency

\section{Introduction}

The world's population has been continuously increasing and is expected to exceed 9.7 billion in 2050 (United Nations Department of Economic and Social Affairs, 2019), which would severely threaten global food security (Bahar et al., 2020). Ensuring food security has become an imperative issue, especially in a developing country like China that has a national population of 1.4 billion (Liang et al., 2019; Gu et al., 2019). A recent study pointed out that developing dryland agriculture in regions like Xinjiang (located in Northwest China, with semi-arid climate) would likely be the new solution for China's food security problem (Gu et al., 2019). In the past two decades, drip irrigation under film mulch has been adopted in large-scale areas of Xinjiang to improve the crop yield per hectare for monoculture maize (Zea mays L.) or cotton (Gossypium hirsutum L.) (Dai et al., 2014; Ning et al., 2015). In these cropping systems, only single crop (maize or cotton) was planted in the filmmulching strips while the bare soil area between the film mulch rows is wasted. Hence, it is important to improve the land use efficiency and agricultural resource (e.g., light, temperature, water, soil nutrients) utilization in the dryland region where arable land is limited (Gu et al., 2019). One potential way to achieve these 
goals is by intercropping or relay intercropping that are mutually beneficial to improve the physical and chemical properties of soil and the ecological environment of the farmland (Xia et al., 2013; Du et al., 2018). Intercropping and relay intercropping are important strategies to improve crop yield production while saving the environment from destruction (Zhao et al., 2018; Gong et al., 2020) because they increase the utilization rates of agricultural resources and minimize the uses of pesticides and fertilizers (Sun et al., 2018; Li et al., 2003). The yield advantage of intercropping is mainly due to the enhanced interspecies interactions (Raza et al., 2019), and the positive changes in interspecies competition and promotion are critical for improving the utilization rates of agricultural resources (Landhäusser et al., 2006; Hu et al., 2016). Some studies reported that intercropping could reduce the interspecies competition for resources as compared to monocropping (Fan et al., 2006; Li et al., 2003). The reduction in interspecies competition could lead to interspecies promotion. According to the "competition-restoration-production principle", early harvesting of early-sown species has a potential restoration effect on the growth of later-harvesting species (Gong et al., 2020; Li et al., 2001a, 2001b; Xia et al., 2013).

In China, intercropping and relay intercropping (e.g., maize and soybean) has been adopted widely to increase the utilization of agricultural resources (Gong et al., 2020). However, little attention has been paid to intercropping of a main food crop and a cash crop (spice crop) like the cumin/maize intercropping. Maize is an important food and forage crop around the world, and China is one of the largest maize producers. Cumin is the world's second largest spice crop; it has a relatively short growth period and high economic value. The cumin/maize intercropping system has the potential to maximize the utilization of agricultural resources, especially during the early growing season of maize. Though the cumin/maize intercropping system has a long history of cultivation in the arid areas of Northwest China, few studies have focused on its performance in crop growth, interspecies interactions, and water use efficiency etc. This study provides experimental basis for local agricultural circles to adjust planting system and improve the utilization rate of agricultural resources.

The objectives of this paper were to: (i) quantify above-ground biomass, crop output, economic benefits, LER, WUE, and WER in the cumin/maize intercropping and monocropping cumin or maize systems to compare the yield advantage and economic efficiency of cumin/maize intercropping and monocropping systems; and (ii) analyze the relative competition intensity $(\mathrm{RCI})$, aggressivity $(\mathrm{Acm})$, relative crowding coefficient $(\mathrm{Kcm})$ of cumin and maize, and determine the intensity of competitiveness of cumin and maize on resources and which is the dominant species.

\section{Materials and Methods}

\subsection{Experimental Site}

The field experiment was conducted in 2019 and 2020 at an experimental site in Bohu county of Xinjiang in China. The experimental site $\left(44.99^{\circ} \mathrm{N}\right.$ and $86.73^{\circ} \mathrm{E}$, Figure 1) is located at the southern foot of Tian Shan (meaning the Heavenly Mountain) and in the southeastern Yanji Basin and the lower reaches of Kaidu River, with an elevation of $1,064 \mathrm{~m}$. The soil type at the experimental site is irrigated meadow soil; the parent material is sandy loam soil, and the soil properties in the top 0-20 cm depth are as follows: organic matter content 21.2 $\mathrm{g} \cdot \mathrm{kg}^{-1}$, available N $84 \mathrm{mg} \cdot \mathrm{kg}^{-1}$, available P $23.1 \mathrm{mg} \cdot \mathrm{kg}^{-1}$, and available K $109.3 \mathrm{mg} \cdot \mathrm{kg}^{-1}$. The experimental site has a semi-arid continental climate, with an average annual temperature of $8.5^{\circ} \mathrm{C}$, annual sunshine duration of $3,008-3,150$ hours and frost-free season length of 215 days. During the growing season (from March to October), precipitation was $157 \mathrm{~mm}$ in 2019 and $244 \mathrm{~mm}$ in 2020, daily average temperature was $17.8^{\circ} \mathrm{C}$ in 2019 and $17.1^{\circ} \mathrm{C}$ in 2020 at the experimental site. 


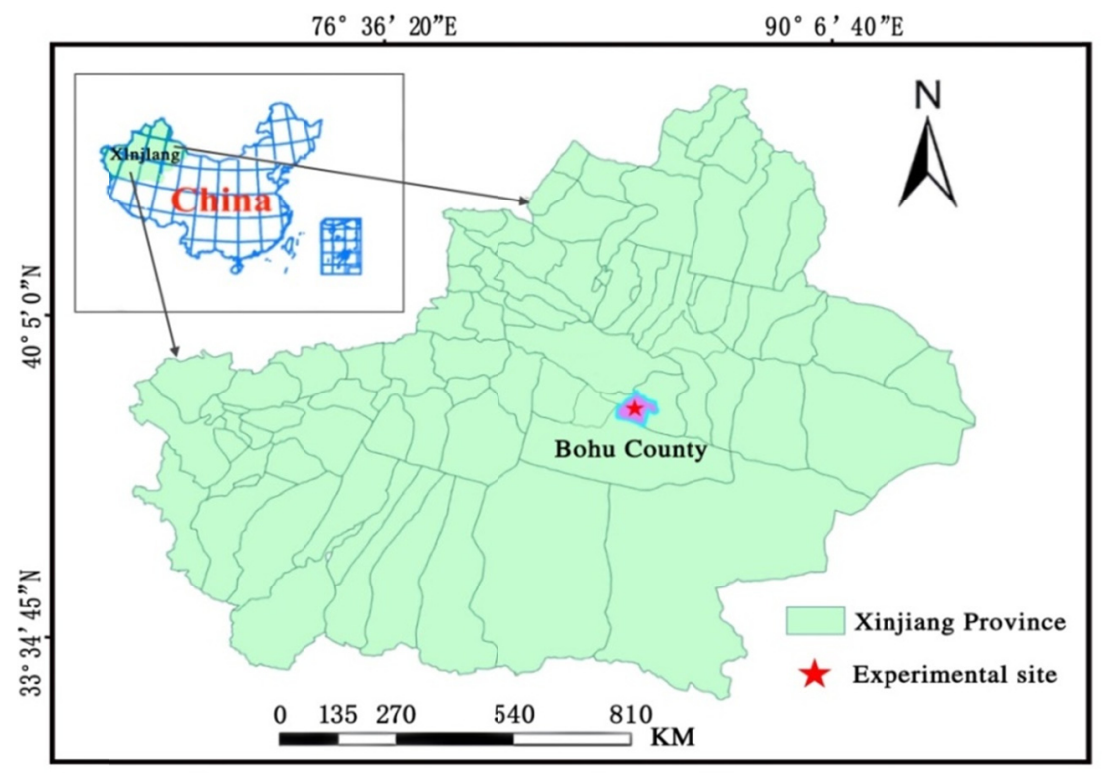

Figure 1. The location of experimental site

\subsection{Experimental Design}

At the experimental location, the prevailing cropping system is monocropping maize with drip irrigation under film mulch. Our experiment consists of three cropping systems: the monocropping maize system, the monocropping cumin system, and the cumin/maize intercropping system (The three cropping systems are all the actual cropping systems produced in local fields). The selected cumin variety was Cumin-6 and maize variety was Liaodan-588. Each cropping system had three replicates, with all plants grown in east-west oriented rows. Each experimental plot was $24 \mathrm{~m}^{2}(4 \mathrm{~m} \times 6 \mathrm{~m})$, with at least four complete rows of crop plants. All experimental plots were set to be $2 \mathrm{~m}$ away from each other in order to avoid lateral and bordering effects. In monocropping maize, the row spacing was $0.3 \mathrm{~m}$; in monocropping cumin, the row spacing was $0.2 \mathrm{~m}$; in intercropping of maize and cumin, the row spacing was $0.2 \mathrm{~m}$ between maize and cumin (Figure 2). Maize was planted at a spacing of $0.28 \mathrm{~m}$. Monocropping and intercropping cumin was sowed at 8 March 2019 and 5 March 2020; Monocropping maize was sowed at 18 April 2019 and 20 April 2020; Intercropping maize was sowed at 12 May 2019 and 8 May 2020, respectively. The total fertilization rate of monocrop and intercrop maize wer $300 \mathrm{~kg} \cdot \mathrm{ha}^{-1}$ of diammonium phosphate, $75 \mathrm{~kg} \cdot \mathrm{ha}^{-1}$ of urea and stable manure $30 \mathrm{t}^{\mathrm{ha}} \mathrm{ha}^{-1}$. The fertilization rates of monocrop cumin were $300 \mathrm{~kg} \cdot \mathrm{ha}^{-1}$ diammonium phosphate, $150 \mathrm{~kg} \cdot \mathrm{ha}^{-1}$ urea and stable manure $30 \mathrm{t} \cdot \mathrm{ha}^{-1}$, all of which were used as base fertilizer. Local standards of agricultural management practices (e.g., irrigation weed, insect control, intertillage, and plant pruning) were strictly followed in the field experiment. 

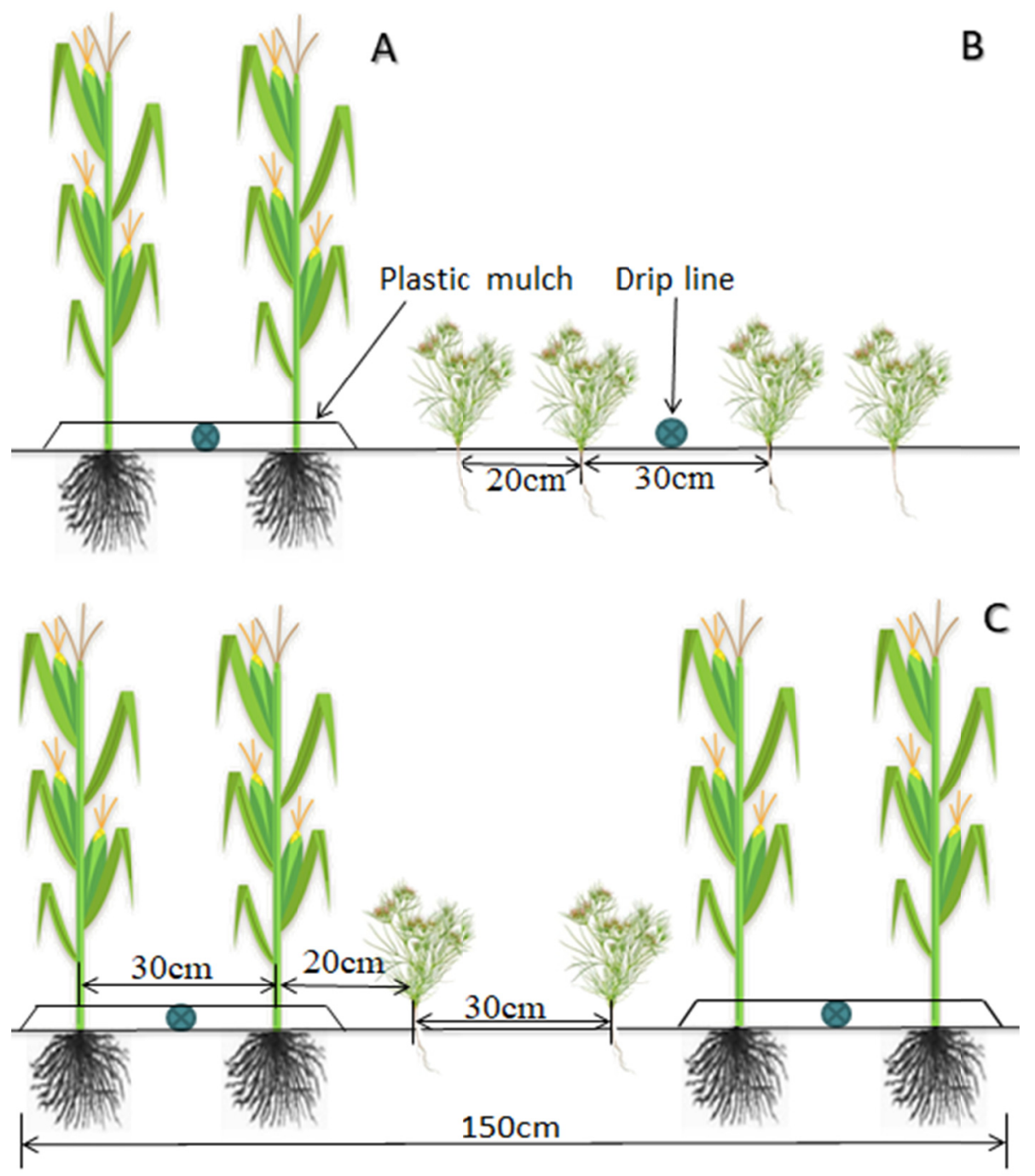

Figure 2. Schematic diagrams of the three study cropping systems at the experimental site in Xinjiang, China (A and B represent monocropping maize and monocropping cumin, respectively; $\mathrm{C}$ represents the cumin/maize intercropping)

\subsection{Measurements and Indices}

\subsubsection{Plant Height, Stem Diameter, and Leaf Area Index}

During flowering stages, grouting stage, and mature stage of 2019 and 2020, randomly selected three representative cumin and maize plants from each plot to measure plant height, stem diameter; At the same time, three representative maize plants were randomly selected from each plot for leaf area determination. LAI was the total leaf area divided by the land area occupied by the plant (Liang et al., 2019; Watson et al., 1947).

\subsubsection{Aboveground Dry Matter, Yield, Total Land Output (TLO)}

At mature stage, five representative cumin or maize plants were collected from each plot, then the aboveground parts of cumin and corn were separated and dried to constant weight in an oven at $85^{\circ} \mathrm{C}$. The aboveground dry matter of cumin and maize were determined by gravimetric method.

Thirty maize plants (five plants from each experiment) were randomly selected from the same area to investigate the spike length, spike number per plant, grain weight per plant and 100-grain weight for maize at harvest. Similarly, the number of branches per plant, number of umbels per plant, grain weight per plant and 1000-grain weight of cumin in each plot were measured at harvest. Grain from each plot was threshed separately. The grain yields were measured after 2-3 weeks of air dried at a moisture content of $12-14 \%$ (grain moisture content was measured with a grain moisture meter). 
In intercropped system, total land output (TLO) was used to evaluate the cumin/maize intercropping productivity as follows:

$$
\mathrm{TLO}=\mathrm{Yic}+\mathrm{Yim}
$$

Where, TLO is total land output, $\mathrm{kg} \cdot \mathrm{ha}^{-1}$; Yic is cumin yield, $\mathrm{kg} \cdot \mathrm{ha}^{-1}$; Yim is maize yield, $\mathrm{kg} \cdot \mathrm{ha}^{-1}$ (Liang et al., 2019; Jolliffe et al., 1999).

\subsubsection{System Productivity and Interspecific Competition}

The land equivalent ratio (LER) is calculated method as follows (Gong et al., 2020; Yin et al., 2017):

$$
\mathrm{LER}=(\mathrm{Yic} / \mathrm{Ymc})+(\mathrm{Yim} / \mathrm{Ymm})
$$

Where Ymc and Yic represent the monocropped and intercropped cumin yields, respectively; Ymm and Yim represent the monocropped and intercropped maize yields, respectively. LER $>1$ indicates that the productivity of the intercropping system is greater than the sum of the productivity of the constituent species in the monocropping system.Yic/Ymc and Yim/Ymm are partial land equivalent ratio (PLER) of cumin and maize, respectively. Their significance lies in the area of monoculture crops needed to obtain the same yield as intercropping component crops.

Relative competition intensity (RCI) refers to the competitiveness of a specific crop combination. According to crop yield, the formula is as follows (Zhao et al., 2020):

$$
\begin{aligned}
\mathrm{RCIc} & =[(\mathrm{Ymc} \times \mathrm{Zic})-\mathrm{Yic}] /(\mathrm{Ymc} \times \mathrm{Zic}) \\
\mathrm{RCIm} & =[(\mathrm{Ymm} \times \mathrm{Zim})-\mathrm{Yim}] /(\mathrm{Ymm} \times \mathrm{Zim})
\end{aligned}
$$

In the formula, Yic and Yim, Ymc and Ymm have the same meaning as formula (1) (2). Zic and Zim are the proportions of intercropped cumin and maize in the intercropping system, respectively. In this study, Zic and Zim were both 0.5 . $\mathrm{RCI}=0$, interspecific competition equals intraspecific competition; $\mathrm{RCI}>0$, interspecific competition is higher; $\mathrm{RCI}<0$, intraspecific competition is higher.

Aggressivity (Acm) refers to the competitiveness of a crop relative to another crop in the intercropping model for water, nutrients, and other resources related to yield formation, and was calculated as follows (Zhao et al., 2020; Dhima et al., 2007):

$$
\mathrm{Acm}=\mathrm{Yic} /(\mathrm{Ymc} \times \mathrm{Zic})+\mathrm{Yim} /(\mathrm{Ymm} \times \mathrm{Zim})
$$

Here, if Acm $>0$, then cumin is the dominant species in the cumin/maize intercropping system; if Acm $<0$, then maize is the dominant species in the cumin/maize intercropping system.

The relative crowding coefficient (Rcm):according to plant competition theory, Rcm in intercropping systems is another indicator of the relative competitive ability between species, and is used here to evaluate the competitive ability of cumin relative to maize in mixed cropping, as follows (Zhao et al., 2020; Bi et al., 2019):

$$
\mathrm{Rcm}=\frac{\mathrm{YIC} \times \mathrm{ZIM}}{(\mathrm{YMC}-\mathrm{YIC}) \times \mathrm{ZIC}} / \frac{\mathrm{YIM} \times \mathrm{ZIC}}{(\mathrm{YMM}-\mathrm{YIM}) \times \mathrm{ZIM}}
$$

If $\mathrm{Rcm}>1$, cumin is more competitive than maize in the cogrowth stage; if $\mathrm{Rcm}<1$, cumin is less competitive than maize.

\subsubsection{Soil Water Content, WUE, WER}

The soil water content was measured every $20 \mathrm{~cm}$ at a soil depth of 0-80 cm via oven drying using an soil auger, taking care to keep damage to a minimum. The measurements were carried out two times during the growing season of each year-before planting and again after harvest-for cumin and maize. In the intercropping system, measurements were taken at one middle location between the rows of the same crop species (including for both cumin and maize). In monocropping system, measurements were taken at a position in the middle of each plot.

The WUE was calculated by the following formula (Liang et al., 2019; Ren et al., 2017):

$$
\mathrm{WUE}=\mathrm{Y} / \mathrm{ET}
$$

Where, $\mathrm{Y}$ is the grain yield $\left(\mathrm{kg} \cdot \mathrm{ha}^{-1}\right)$ and $\mathrm{ET}(\mathrm{mm})$ is evapotranspiration (Liang et al., 2019; Sun et al., 2018):

$$
\mathrm{ET}=\mathrm{P}+\mathrm{I}+\mathrm{G}-\mathrm{R}-\mathrm{D}-\Delta \mathrm{W}
$$

Where, $\mathrm{P}$ is precipitation during growth, $\mathrm{mm}$; I is total irrigation, $\mathrm{mm}$; $\mathrm{G}$ is groundwater recharge, $\mathrm{mm}$; D is deep seepage, $\mathrm{mm} ; \mathrm{R}$ is runoff, $\mathrm{mm} . \Delta \mathrm{W}$ is the difference between soil water storage before sowing and soil water storage at harvest, $\mathrm{mm}$ (Liang et al, 2019). The level of groundwater in the experimental site was below $7.5 \mathrm{~m}$. In addition, no unplanned irrigation was used during the experiment. Therefore, G, D, and R were neglected. 
Water equivalent ratio (WER): WER is a quantitative evaluation of water use efficiency (WUE) of intercropping patterns by comparing with that of monocropping crops. Calculate with the following formula (Gao et al., 2017):

$$
\mathrm{WER}=(\mathrm{WUEic} / \mathrm{WUEmc})+(\text { WUEim/WUEmm })
$$

WUEic and WUEmc are water use efficiency of cumin under intercropping and monocropping, wueim and wuemm are water use efficiency of Maize under intercropping and monocropping. When the water equivalent ratio $($ WER) $<1$, it indicated that intercropping decreased the water use efficiency of crops compared with monoculture; if not, the intercropping pattern improved the water use efficiency.

\subsubsection{Economic Benefits}

Material inputs, including cumin seed, maize seed, fertilizer, plastic film, labor cost, pesticide, farm machinery, and irrigation water. The output value is cumin and maize. The selling price includes seed cumin was $3.19 \$ \mathrm{~kg}^{-1}$ and $2.61 \$ \mathrm{~kg}^{-1}$ in 2019 and 2020; maize was $0.26 \$ \cdot \mathrm{kg}^{-1}$ and $0.38 \$ \mathrm{~kg}^{-1}$ in 2019 and 2020.The input of seed cumin was $4.64 \$ \cdot \mathrm{kg}^{-1}$ and $5.07 \$ \cdot \mathrm{kg}^{-1}$ in 2019 and 2020 , respectively; and seed maize was $3.19 \$ \cdot \mathrm{kg}^{-1}$ and 3.62 $\$ \cdot \mathrm{kg}^{-1}$ in 2019 and 2020, respectively. The other material inputs were determined based on current market prices for 2019 and 2020. The exchange rate be based on the average exchange rate of the current year. Exchange rate was $1 \$ \approx 6.90 Y$ in 2019 and $1 \$ \approx 6.93 ¥$ in 2020 . The economic benefits was calculated by the following formula:

$$
\text { Economicbenefits }=\text { Totaloutputvalue }- \text { Totalinputvalue }
$$

\subsection{Statistical Analysis}

All the experimental data were managed by Microsoft Excel 2010, and the figures were constructed with SigmaPlot 12.5, Origin Pro 2018. SPSS Statistics 17.0 software was used to analysis of variance(ANOVA). Graphics are created by the SigmaPlot 12.5, Origin Pro 2018, and ArcGIS 10.5.

\section{Results}

\subsection{Crop Growth and Yield}

There were significant differences in plant height, stem diameter, and LAI among the three study cropping systems in 2019 and 2020 at the experimental site. The plant height and stem diameter of intercropped cumin was $17.9 \%$ and $51.6 \%$ greater than that of monocropped cumin. By contrast, the plant height, stem diameter, and LAI of intercropped maize were reduced as compared to monocropped maize, by $22.7 \%, 17.8 \%$, and $7.9 \%$, respectively (Table 1). The number of seeds per plant and 1000-seed weight of intercropped cumin were significantly improved as compared to monocropped cumin, by $11.9 \%$ and $37.2 \%$, respectively. By contrast, the number of grains per plant and 100-grain weight of intercropped maize was reduced as compared to monocropped maize, by $8.2 \%$ and $3.9 \%$, respectively (Table 2 ). The yield of the cumin/maize intercropping system was significantly lower than the yield of monocropping cumin and maize, with a reduction rate of $22.5 \%$, $11.7 \%$ (Table 3). LER of the cumin/maize intercropping system was greater than 1 in both of the experimental years, indicating that more area would be required to produce the same amount of crop yields in the monocropping system than in the cumin/maize intercropping system. The cumin/maize intercropping system could increase the crop yields by $65.0 \%$ compared to cultivating them separately (Table 4 ). The economic profit of both monocropping cumin or monocropping maize was significantly lower than the cumin/maize intercropping system, In sum, the cumin/maize intercropping system showed a better potential in achieving higher land use efficiency and economic profit than the monoculture of maize or cumin. 
Table 1. Effects of cropping system on growth parameters of cumin and maize in 2019 and 2020

\begin{tabular}{|c|c|c|c|c|c|c|}
\hline \multirow{2}{*}{ Year } & \multirow{2}{*}{ Cropping system } & \multicolumn{2}{|c|}{ Cumin } & \multicolumn{3}{|c|}{ Maize } \\
\hline & & Plant height $(\mathrm{mm})$ & Stem diameter $(\mathrm{mm})$ & Plant height $(\mathrm{mm})$ & Stem diameter $(\mathrm{mm})$ & LAI \\
\hline \multirow{2}{*}{2019} & Monocropping & $25.1 \pm 0.9 \mathrm{~b}$ & $1.4 \pm 0.1 \mathrm{~b}$ & $296.3 \pm 5.2 \mathrm{a}$ & $28.6 \pm 1.4 \mathrm{a}$ & $5.6 \pm 0.3 \mathrm{a}$ \\
\hline & Intercropping & $30.6 \pm 1.0 \mathrm{a}$ & $2.2 \pm 0.2 \mathrm{a}$ & $230.4 \pm 8.6 \mathrm{~b}$ & $23.6 \pm 0.9 \mathrm{~b}$ & $5.1 \pm 0.3 \mathrm{~b}$ \\
\hline \multirow{2}{*}{2020} & Monocropping & $26.3 \pm 0.8 \mathrm{~b}$ & $1.5 \pm 0.1 \mathrm{~b}$ & $308.6 \pm 1.9 \mathrm{a}$ & $30.0 \pm 1.3 \mathrm{a}$ & $6.2 \pm 0.2 \mathrm{a}$ \\
\hline & Intercropping & $31.0 \pm 1.2 \mathrm{a}$ & $2.3 \pm 0.2 \mathrm{a}$ & $237.6 \pm 7.0 \mathrm{~b}$ & $25.0 \pm 1.0 \mathrm{~b}$ & $5.9 \pm 0.2 b$ \\
\hline
\end{tabular}

Note. Letters following "mean \pm standard deviation" in the columns represent significance between the cropping systems at the 0.05 level; "ns" means no significant. Growth index of cumin and maize in monocropping cumin system, monocropping maize system, and cumin/maize intercropping system was measured at the maturre stage in 2019 and 2020.

$\mathrm{PH}, \mathrm{SD}$, LAI represent plant height, stem diameter, and leaf area index, respectively.

Same definitions apply in the remaining Tables 2-5.

Table 2. Effects of cropping system on yield components of cumin and maize

\begin{tabular}{llllll}
\hline \multirow{2}{*}{ Year } & \multirow{2}{*}{ Cropping system } & \multicolumn{2}{c}{ Cumin } & \multicolumn{2}{c}{ Maize } \\
\cline { 3 - 6 } & & Number of seeds per plant & 1000 -seed weight $(\mathrm{g})$ & Number of grains per plant & 100 -grain weight $(\mathrm{g})$ \\
\hline \multirow{2}{*}{2019} & Monocropping & $300 \pm 34.8 \mathrm{~b}$ & $30.7 \pm 1.8 \mathrm{~b}$ & $619 \pm 18.1 \mathrm{a}$ & $35.6 \pm 4.0 \mathrm{a}$ \\
& Intercropping & $321 \pm 13.4 \mathrm{a}$ & $43.2 \pm 0.8 \mathrm{a}$ & $576 \pm 14.6 \mathrm{~b}$ & $34.0 \pm 6.3 \mathrm{~b}$ \\
\hdashline 20 & Monocropping & $295 \pm 54.6 \mathrm{~b}$ & $32.5 \pm 0.9 \mathrm{~b}$ & $710 \pm 11.2 \mathrm{a}$ & $35.8 \pm 5.6 \mathrm{a}$ \\
& Intercropping & $345 \pm 17.5 \mathrm{a}$ & $43.7 \pm 0.6 \mathrm{a}$ & $644 \pm 25.6 \mathrm{~b}$ & $34.7 \pm 7.7 \mathrm{~b}$ \\
\hline
\end{tabular}

Table 3. Effects of cropping system on aboveground dry matter, yields, TLO of cumin and maize in 2019 and 2020

\begin{tabular}{|c|c|c|c|c|c|c|}
\hline \multirow{2}{*}{ Year } & \multirow{2}{*}{ Cropping system } & \multicolumn{2}{|c|}{ Above-ground dry matter $\left(\mathrm{kg} \cdot \mathrm{ha}^{-1}\right)$} & \multicolumn{2}{|c|}{ Yield $\left(\mathrm{kg} \cdot \mathrm{ha}^{-1}\right)$} & \multirow{2}{*}{ Total crop output $\left(\mathrm{kg} \cdot \mathrm{ha}^{-1}\right)$} \\
\hline & & Cumin & Maize & Cumin & Maize & \\
\hline \multirow{3}{*}{2019} & Monocropping cumin & $4559.9 \pm 772.6 \mathrm{a}$ & $\mathrm{n} / \mathrm{a}$ & $1598.4 \pm 156.6 \mathrm{a}$ & $\mathrm{n} / \mathrm{a}$ & $1598.4 \pm 156.6 \mathrm{c}$ \\
\hline & Monocropping maize & $\mathrm{n} / \mathrm{a}$ & $27183.9 \pm 471.4 \mathrm{a}$ & $\mathrm{n} / \mathrm{a}$ & $14977.6 \pm 578.6 \mathrm{a}$ & $14977.6 \pm 578.6 \mathrm{a}$ \\
\hline & Cumin-maize intercropping & $3916.6 \pm 845.5 b$ & $25378.2 \pm 811.9 \mathrm{~b}$ & $1211.5 \pm 86.7 b$ & $13307.3 \pm 581.4 \mathrm{~b}$ & $14518.7 \pm 668.1 \mathrm{~b}$ \\
\hline \multirow{3}{*}{2020} & Monocropping cumin & $4819.2 \pm 899.4 \mathrm{a}$ & $\mathrm{n} / \mathrm{a}$ & $1720.8 \pm 307.0 \mathrm{a}$ & $\mathrm{n} / \mathrm{a}$ & $1720.8 \pm 307.0 \mathrm{c}$ \\
\hline & Monocropping maize & $\mathrm{n} / \mathrm{a}$ & $28852.2 \pm 363.3 \mathrm{a}$ & $\mathrm{n} / \mathrm{a}$ & $17306.8 \pm 530.6 \mathrm{a}$ & $17306.8 \pm 530.6 \mathrm{a}$ \\
\hline & Cumin-maize intercropping & $4217.1 \pm 554.1 \mathrm{~b}$ & $26774.9 \pm 290.3 b$ & $1355.5 \pm 106.0 \mathrm{~b}$ & $15193.3 \pm 817.8 b$ & $16548.8 \pm 923.9 \mathrm{~b}$ \\
\hline
\end{tabular}

Table 4. LER (mean \pm SD) of component crops for the intercropping of maize and cumin in 2019 and 2020

\begin{tabular}{lllll}
\hline Year & Cropping system & Partial LER of cumin & Partial LER of maize & LER \\
\hline 2019 & Cumin-maize intercropping & $0.76 \pm 0.05$ & $0.87 \pm 0.03$ & $1.63 \pm 0.08$ \\
2020 & Cumin-maize intercropping & $0.79 \pm 0.06$ & $0.88 \pm 0.05$ & $1.67 \pm 0.11$ \\
\hline
\end{tabular}

Table 5. Effects of cropping system on output, input, and benefit (unit: \$·hm ${ }^{-1}$ ) in 2019 and 2020.

\begin{tabular}{lllll}
\hline Year & Cropping system & Input cost $\left(\$ \cdot \mathrm{ha}^{-1}\right)$ & Output market value $\left(\$ \cdot \mathrm{ha}^{-1}\right)$ & Unrealized economic profit $\left(\$ \cdot \mathrm{ha}^{-1}\right)$ \\
\hline \multirow{2}{*}{2019} & Monocropping cumin & $5,097 \pm 499 \mathrm{~b}$ & $1,194 \pm 49 \mathrm{c}$ & $3,903 \pm 450 \mathrm{~b}$ \\
& Monocropping maize & $3,928 \pm 140 \mathrm{c}$ & $2,144 \pm 107 \mathrm{~b}$ & $1,784 \pm 33 \mathrm{c}$ \\
& Cumin-maize intercropping & $7,343 \pm 225 \mathrm{a}$ & $2,361 \pm 57 \mathrm{a}$ & $4,982 \pm 168 \mathrm{a}$ \\
\multirow{2}{*}{2020} & Monocropping cumin & $4,466 \pm 501 \mathrm{c}$ & $1,321 \pm 63 \mathrm{c}$ & $3,145 \pm 438 \mathrm{c}$ \\
& Monocropping maize & $6,481 \pm 201 \mathrm{~b}$ & $2,314 \pm 64 \mathrm{~b}$ & $3,870 \pm 137 \mathrm{~b}$ \\
& Cumin-maize intercropping & $9,207 \pm 216 \mathrm{a}$ & $2,548 \pm 49 \mathrm{a}$ & $6,659 \pm 167 \mathrm{a}$ \\
\hline
\end{tabular}

\subsection{Interspecific Interactions}

For the cumin/maize intercropping system, RCI of cumin and RCI of maize were both lower than zero, indicating that the intraspecies competition was stronger than the interspecies competition. In other words, cumin/maize intercropping system is a reciprocal cropping system. The aggressivity of cumin vs. maize was 
smaller than 0 in both 2019 and 2020, indicating that maize was the dominant species and therefore more competitive for resources like water and nutrients. Rcm of cumin vs. maize was also smaller than 0 , indicating that maize was more competitive than cumin during the cogrowth period and had better advantages in interspecific interactions (Table 6)

Table 6. Relative competition intensity (RCI), aggressivity (Acm), and relative crowding coefficient ( $\mathrm{Rcm})$ as affected by cumin/maize intercropping system in 2019 and 2020

\begin{tabular}{llllll}
\hline Year & Cropping system & RCI of cumin & RCI of maize & Acm (cumin vs. maize) & Rcm (cumin vs. maize) \\
\hline 2019 & Cumin-maize intercropping & $-0.46 \pm 0.06$ & $-0.71 \pm 0.06$ & $-0.25 \pm 0.18$ & $-3.09 \pm 0.50$ \\
2020 & Cumin-maize intercropping & $-0.60 \pm 0.05$ & $-0.79 \pm 0.09$ & $-0.19 \pm 0.03$ & $-3.20 \pm 0.24$ \\
\hline
\end{tabular}

\subsection{Water Use Efficiency (WUE) and Water Equivalent Ratio (WER)}

In the three study cropping systems, soil water content of both cumin and maize showed a gradual increase with the increase of soil depth. At the same soil depth, soil water content in the intercropping system was significantly higher than soil water content in the monocropping systems (Figures 3 and 4). The WUE for cumin/maize intercropping was 51-59\% higher than the WUE for monocropping cumin but $9-15 \%$ lower than the WUE for monocropping maize (Figure 5). Water equivalent ratio (WER) for cumin/maize intercropping system was greater than 1 in both 2019 and 2020, implying that maize/cumin intercropping had an advantage in water use efficiency compared to cultivating the monocropping cumin and monocropping maize (Table 7).
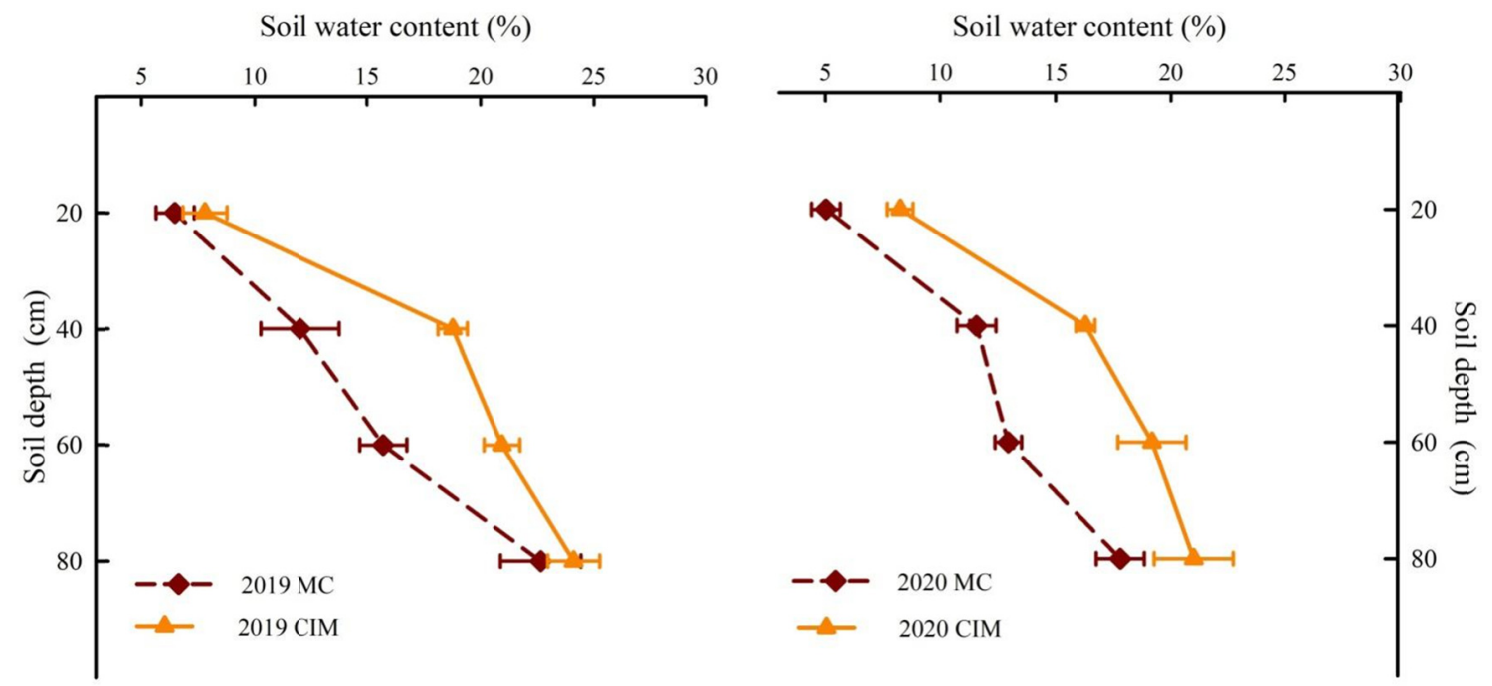

Figure 3. Soil water content of cumin at maturity under intercropping and monocropping system

in 2019 and 2020 

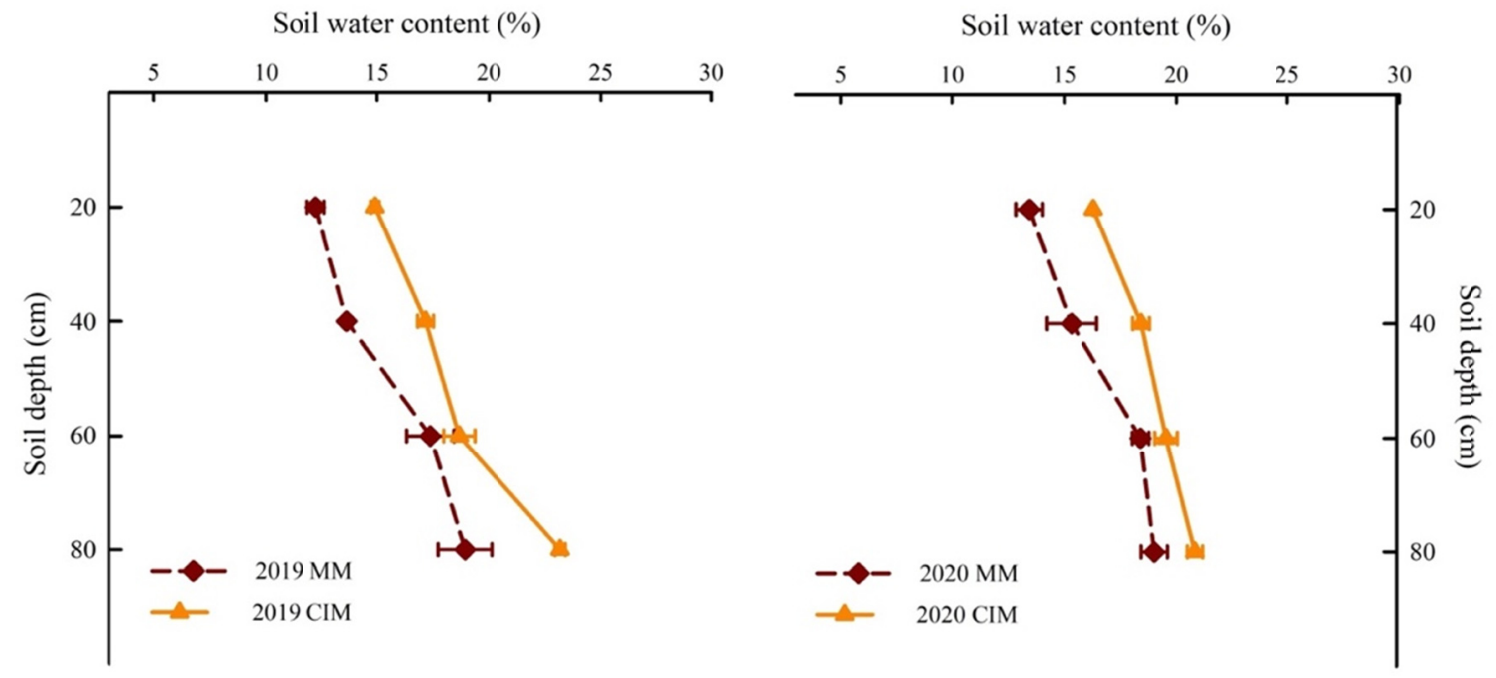

Figure 4. Soil water content of maize at maturity under intercropping and monocropping system in 2019 and 2020

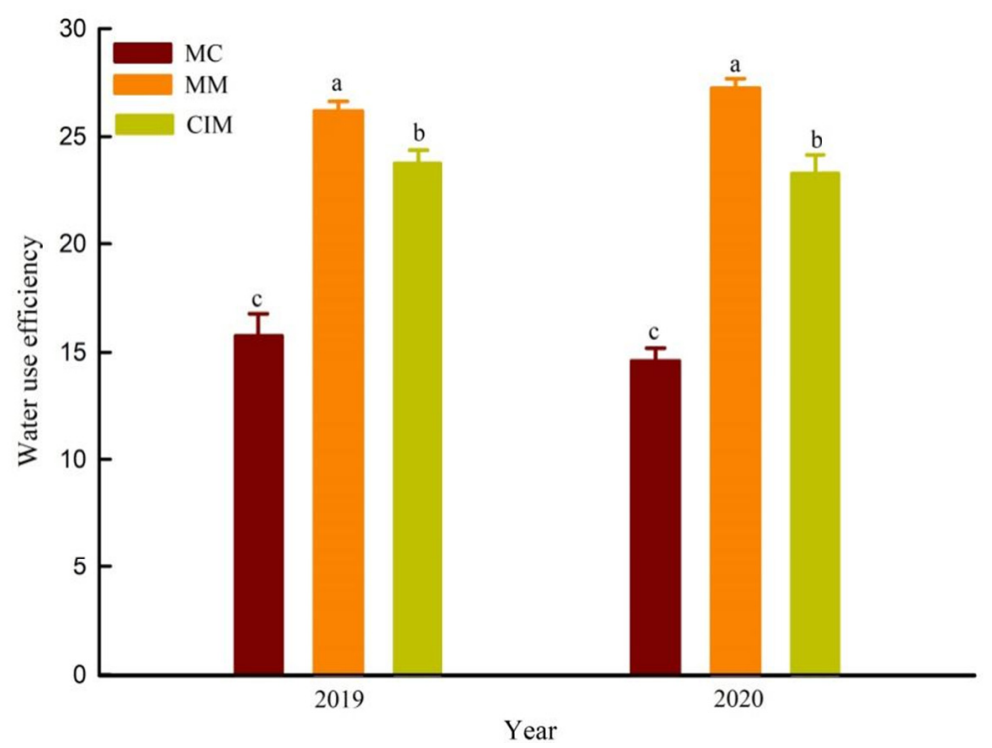

Figure 5. Water use efficiency (WUE) of intercropping and monocropping system in 2019 and 2020

Table 7. Water equivalent ratio (WER) of interplanting system in 2019 and 2020

\begin{tabular}{lllll}
\hline Year & Cropping system & Partial WER of cumin & Partial WER of maize & WER \\
\hline 2019 & Cumin-maize intercropping & $0.75 \pm 0.04$ & $0.90 \pm 0.02$ & $1.65 \pm 0.06$ \\
2020 & Cumin-maize intercropping & $0.81 \pm 0.04$ & $0.87 \pm 0.03$ & $1.68 \pm 0.07$ \\
\hline
\end{tabular}

\section{Discussion}

\subsection{Yield Production and Interspecific Interactions of the Intercropping System}

Intercropping could effectively improve the utilization rates of agricultural resources and crop yields output per unit area compared with typical production of each crop separately, though some changes in routine agricultural management are required, like changes in the allocation time and spatial layout of interspecific crops as well as adjustments in sowing/planting dates (Echarter et al., 2011; Vazin et al., 2013; Koocheki et al., 2016). In our two-year field experiment in a semi-arid area of Xinjiang, China, compared with the monocropping system, the cumin/maize intercropping system promoted the growth and development of above-ground parts (plant height 
and stem diameter) of cumin and showed a suppressive effect on above-ground parts of maize. The intercropping system changes the micro-environment for crop growth and development, ultimately improving the utilization of agricultural resources. The cumin/maize intercropping system significantly increased the number of seeds per plant and 1000-seed weight of cumin compared with monocropping cumin; but the cumin/maize intercropping system significantly decreased the number of grains per plant and 100-grain weight of maize compared with monocropping maize. These results are consistent with the findings in a previous study on the intercropping system of saffron and cumin (Koocheki et al., 2016). In this study, LER for the cumin/maize intercropping system was higher than 1, indicating a pronounced advantage in land use efficiency. In addition, the economic profit for the cumin/maize intercropping system was significantly higher than that for the monocropping systems. These results imply that the cumin/maize intercropping system improve agricultural resource utilization and economic profitability in semi-arid areas of Xinjiang in China.

Interspecific interactions (e.g., the concurrent competition and promotion) in intercropping system are important factors affecting the utilization rates of agricultural resources in component crops. In this experiment, the cumin/maize intercropping system changed the environment for crop growth, leading to changes in the two crop plants' intake of nutrients and water, etc. and hence changes in interspecific competitiveness (Zhang et al., 2011; Zhao et al., 2013; Zhao et al., 2019; Dong et al., 2018). RCI of cumin and maize for the cumin/maize intercropping system were both lower than 0 , indicating that the interspecific competition was relatively weaker than the intraspecific competition. The aggressivity of cumin vs. maize was also lower than 0 , implying that maize was the dominant species. Meanwhile, the Rcm of cumin against maize was lower than 1.0, implying that maize was more competitive than cumin during the co-growth period. This could be explained by the fact that maize plants are relatively taller than cumin plants, and it occupy an taller ecological niche in the same growing environment (Agegnehu et al., 2006; Fan et al., 2012). And earlier harvest of early seeded species can have a potential recovery effect on the growth of later harvested species (Gong et al., 2020; Xia et al., 2013).

\subsection{Water Use Efficiency (WUE) of Intercropping System}

In an intercropping system, one of the main resources that the component crop plants' roots compete for is soil water. Optimal combinations of component crops can help to reduce the competition for soil water, improve crop water use efficiency, increase the land productivity, and potentially improve the marginal economic profit (Gong et al., 2020; Liang et al., 2019). In this two-year experimental study, soil water content in the top $80 \mathrm{~cm}$ layer for the intercropping system was significantly higher than that for the monocropping systems. The WUE for the intercropping of cumin and maize was much higher than the WUE for monocropping cumin, while the WUE for the cumin/maize intercropping system was still lower than the WUE of monocropping maize. Simply comparing WUE is not enough to conclude which cropping system uses water more efficiently. Therefore, we computed water equivalent ratio (WER) for the the cumin/maize intercropping system in the two experimental years as well. WER for the cumin/maize intercropping system was greater than 1 in both 2019 and 2020, indicating improved water use efficiency compared with each monocropping systems (Mao et al., 2016).

\section{Conclusions}

In conclusion, the cumin/maize intercropping system was a promising agronomicstrategy to improve agricultural resource utilization and economic benefits in Xinjiang of China. Although the yields of intercropped cumin and maize were lower than the yields of monocropped cumin and maize, but the economic benefits of cumin intercropping system made up for the loss of maize yield. The land equivalent ratio (LER) and water equivalent ratio (WER) of cumin/maize intercropping systems showed good intercropping advantages. In addition, the relative competitive intensity (RCIc) of cumin, relative competitive intensity (RCIm) of maize, the relative competitiveness Acm (average - 0.22) and relative crowding coefficient Rcm (average-3.15) of intercropped cumin in the intercropping systems were less than 0 , indicating that the cumin/maize intercropping systems was a reciprocal cropping system in which the intra-species competition of intercropped crops dominated and the inter-species competition was relatively weak, thus reducing the impact on the respective yields to a large extent. Meanwhile, maize was the dominant species in the cumin/maize intercropping systems.

The cumin/maize intercropping system had more advantages than monocropping system in accessing resources like light, heat (i.e., temperature), water, fertilizer, and land, which could improve agricultural resource utilization in the long run. Therefore, the cumin/maize intercropping system has more potential than monocropping cumin or maize to develop sustainable agriculture in the semi-arid area of Xinjiang in China.

\section{Acknowledgments}

This study is part of the Innovation and Development Project from Shihezi University (CXFZ202008) and is supported by National Natural Science Foundation of China (Grant Nos. 31460335 and 31560376). 


\section{References}

Agegnehu, G., Ghizaw, A., \& Sinebo, W. (2006). Yield performance and land-use efficiency of barley and faba bean mixed cropping in Ethiopian highlands. European Journal of Agronomy, 25, 202-207. https://doi.org/ 10.1016/j.eja.2006.05.002

Bahar Nur H. A., Michaela, L., Made, S., Josh, V. V., Peter, A., Amy, I., \& Terry, S. (2020). Meeting the food security challenge for nine billion people in 2050: What impact on forests? Global Environmental Change, 62, 195-215. https://doi.org/10.1016/j.gloenvcha.2020.102056

Bi, Y. X., Zhou, P., Li, S. J., Wei, Y. Q., Xiong, X., Shi, Y. H., ... Zhang, Y. J. (2019). Interspecific interactions contribute to higher forage yield and are affected by phosphorus application in a fully-mixed perennial legumeand grass intercropping system. Field Crops Research, 244, 107636. https://oi.org/10.1016/ j.fcr.2019.107636

Dai, J. L., \& Dong, H. Z. (2014). Intensive cotton farming technologies in China: Achievements, challenges and countermeasures. Field Crops Research, 155, 99-110. https://doi.org/10.1016/j.fcr.2013.09.017

Dhima, K. V., Lithourgidis, A. S., Vasilakoglou, I. B., \& Dordas, C. A. (2007). Competition indices of common vetch and cereal intercrops in two seeding ratio. Field Crops Research, 100, 249-256. https://doi.org/ 10.1016/j.fcr.2006.07.008

Dong, N., Tang, M. M., Zhang, W. P., Bao, X. G., Wang, Y., Christie, P., \& Li, L. (2018). Temporal differentiation of crop growth as one of the drivers of intercropping yield advantage. Entific Reports, $8(1)$, 3110. https://doi.org/10.1038/s41598-018-21414-w

Du, J. B., Han, T. F., Gai, J. Y., Yong, T. W., Sun, X., Wang, X. C., ... Yang, W. Y. (2018). Maize-soybean strip intercropping: achieved a balance between high productivity and sustainability. Journal of Integrative Agriculture, 17(4), 747-754. https://doi.org/10.1016/S2095-3119(17)61789-1

Echarter, L., Maggioea, D. A., Cerrudo, D., Gonzalez, V. H., Abbate, P., Cerrudo, A., ... Calvino, P. (2011). Yield response to plant density of maize and sunflower intercropped with soybean. Field Crops Research, 121(3), 423-429. https://doi.org/10.1016/j.fcr.2011.01.011

Fan, F. L., Zhang, F. S., Song, Y. N., Sun, J. H., Bao, X. G., Guo, T. W., \& Li, L. (2006). Nitrogen Fixation of Faba Bean (Vicia faba L.) Interacting with a Nonlegume in Two Contrasting Intercropping Systems. Plant Soil, 283(1-2), 275-286. https://doi.org/10.1007/s11104-006-0019-y

Fan, Z. L., Chai, Q., Huang, G. B., Yu, A. Z., Huang, P., Yang, C. H., ... Liu, H. L. (2012). Yield and water consumption characteristics of wheat/maize intercropping with reduced tillage in an oasis region. European Journal of Agronomy, 25121, 1-7. https://doi.org/10.1016/j.eja.2012.10.010

Gao, Y. (2017). Effects of farmland productivity and water use in maize/peanut intercropping system. Shenyang Agricultural University.

Gong, X. W., Dang, K., Lv, S. M., Zhao, G., Tian, L. X., Luo, Y., \& Fang, B. L. (2020). Interspecific root interactions and water-use efficiency of intercropped proso millet and mung bean. European Journal of Agronomy, 115, 126034. https://doi.org/10.1016/j.eja.2020.126034

Gu, X. B., Cai, H. J., Zhang, Z. T., Fang, H., Chen, P. P., Huang, P., .. Du, Y. D. (2019). Ridge-furrow full film mulching: an adaptive management strategy to reduce irrigation of dryland winter rapeseed (Brassica napus L.) in northwest China. Agricultural and Forest Meteorology, 266, 119-128. https://doi.org/10.1016/ j.agrformet.2018.12.009

Hu, F. L., Gan, Y. T., Chai, Q., Fang, F. X., Zhao, C., Yu, A. Z., ... Zhang, Y. (2016). Boosting system productivity through the improved coordination of interspecific competition in maize/pea strip intercropping. Field Crops Research, 198, 50-60. https://doi.org/10.1016/j.fcr.2016.08.022

Jolliffe, P. A., \&Wanjau, F. M. (1999). Competition and productivity in crop mixtures: some properties of productive intercrops. J. Agricultural Science, 132, 425-435. https://doi.org/10.1017/S0021859699006450

Koocheki, A., Seyyedi, S. M., \& Gharaei, S. (2016). Evaluation of the effects of saffron-cumin intercropping on growth, quality and land equivalent ratio under semi-arid conditions. Entia Horticulturae, 201, $190-198$. https://doi.org/10.1016/j.scienta.2016.02.005

Landhäusser, S. M., Lieffers, V. J., \& Mulak, T. (2006). Effects of soil temperature and time of decapitation on sucker initiation of intact Populus tremuloides root systems. Forest Research, 21, 299-306. https://doi.org/ $10.1080 / 02827580600813313$ 
Li, L., Sun, J. H., Zhang, F. S., Li, X. L., Rengel, Z., \& Yang, S. C. (2001a). Wheat/maize or wheat/soybean strip intercropping: II. Recovery or compensation of maize and soybean after wheat harvesting. Field Crops Research, 71, 173-181. https://doi.org/10.1016/S0378-4290(01)00157-5

Li, L., Sun, J. H., Zhang, F. S., Li, X. L., Yang, S. C., \& Rengel, Z. (2001b). Wheat/maize or wheat/soybean strip intercropping: I. Yield advantage and interspecific interactions on nutrients. Field Crops Research, 71, 123-137. https://doi.org/10.1016/S0378-4290(01)00156-3

Li, L., Zhang, F. S., Li, X. L., Christie, P., Sun, J. H., Yang, S. C., \& Tang, C. X. (2003). Interspecific facilitation of nutrient uptake by intercropped maize and faba bean Interspecific facilitation of nutrient uptake by intercropped maize and faba bean. Nutrient Cycling in Agroecosystems, 65(1), 61-71. https://doi.org/ 10.1023/A:1021885032241

Li, Y. Y., Yu, C. B., Cheng, X., Li, C. J., Sun, J. H., Zhang, F. S., Lambers, H., \& Li, L. (2009). Intercropping alleviates the inhibitory effect of $\mathrm{N}$ fertilization on nodulation and symbiotic $\mathrm{N} 2$ fixation of faba bean. Plant Soil, 323, 295-308. https://doi.org/10.1007/s11104-009-9938-8

Liang, J. P., Shi, W. J., He, Z. J., Pang, L. N., \& Zhang, Y. C. (2019). Effects of poly- $\gamma$-glutamic acid on water use efficiency, cotton yield, and fiber quality in the sandy soil of southern Xinjiang, China. Agricultural Water Manage., 218, 48-59. https://doi.org/10.1016/j.agwat.2019.03.009

Mao, L. L., Li, Y. Z., Hao, W. P., Zhou, X. N., Xu, C. Y., \& Lei, T. W. (2016). A new method to estimate soil water infiltration based on a modified green-ampt model. Soil Tillage Research, 161, 31-37. https://doi.org/ 10.1016/j.still.2016.03.003

Ning, S. R., Shi, J. C., Zuo, Q., Wang, S., \& Ben-Gal, A. (2015). Generalization of the root length density distribution of cotton under film mulched drip irrigation. Field Crops Research, 177, 125-136. https://doi.org/10.1016/j.fcr.2015.03.012

Raza, M. A., Bin Khalid, M. H., Zhang, X., Fang, L. Y., Khan, I., Hassan, M. J., .. Yang, W. Y. (2019). Effect of planting patterns on yield, nutrient accumulation and distribution in maize and soybean under relay intercropping systems. Scientific Reports, 9(1), 4749. https://doi.org/ 10.1038/s41598-019-41364-1

Ren, Y. Y., Wang, X. L., Zhang, S. Q., Alberto, J. A., \& Chen, Y. L. (2017). Influence of spatial arrangement in maize-soybean intercropping on root growth and water use efficiency. Plant Soil, 415(1-2), 131-144. https://doi.org/10.1007/s11104-016-3143-3

Sun, T., Li, Z. Z., Wu, Q., Sheng, T. T., \& Du, M. Y. (2018). Effects of alfalfa intercropping on crop yield, water use efficiency, and overall economic benefit in the Corn Belt of Northeast China. Field Crops Res., 216, 109-119. https://doi.org/10.1016/j.fcr.2017.11.007

Vazin, F. (2013). Water stress effects on cumin (Cuminum cyminum L.) yield and oil essential components. Scientia Horticulturae, 151, 135-141. https://doi.org/10.1016/j.scienta.2012.12.018

Watson, D. J. (1947). Comparative physiological studies in the growth of field crops. I variation in net assimilation rate and leaf area between species and varieties, and within and between years. Ann. Bot., 11, 41-76. https://doi.org/10.1111/j.1744-7348.1953.tb02364.X

Xia, H. Y., Zhao, J. H., Sun, J. H., Bao, X. G., Christie, P., Zhang, F. S., \& Li, L. (2013). Dynamics of root length and distribution and shoot biomass of maize as affected by intercropping with different companion crops and phosphorus application rates. Field Crop Research, 150, 52-62. https://doi.org/10.1016/j.fcr.2013. 05.027

Yin, W., Chai, Q., Guo, Y., Feng, F. X., Zhao, C., Yu, A. Z., ... Chen, G. G. (2017). Reducing carbon emissions and enhancing crop productivity through strip intercropping with improved agricultural practices in an arid area. J. Clean. Prod., 166, 197-208. https://doi.org/10.1016/j.jclepro.2017.07.211

Zhang, G. G., Dong, S. T., \& Yang, Z. B. (2011). Yield performance and interspecific competitiveness evaluation of alfalfa + maize intercropping system. Acta Pratacultural Sinica, 20(01), 22-30.

Zhao, J. H., Sun, J. H., \& Li, W. Q. (2018). Effects of maize sowing date on yield and interspecific competitiveness of soybean/maize intercropping. Chinese Journal of Ecological Agriculture, 26(11), 1634-1642.

Zhao, J. H., Sun, J. H., \& Li, W. Q. (2020). Effects of plastic film mulching on crop productivity and interspecific interaction of maize and pea. Agricultural Research in Arid Areas, 038(2), 164-169. 
Zhao, J. H., Sun, J. H., Chen, W., \& Li, W. Q. (2013). Yield and biomass accumulation of maize intercropped with different crops. Crops, 4, 120-125.

Zhao, J. H., Sun, J. H., Chen, Z. L., \& Li, W. Q. (2019). Growth and interspecific competition of crops as affected by maize row spacing in soybean/maize intercropping system. Agricultural Research in Arid Areas, $33(3), 159-163$

\section{Copyrights}

Copyright for this article is retained by the author(s), with first publication rights granted to the journal.

This is an open-access article distributed under the terms and conditions of the Creative Commons Attribution license (http://creativecommons.org/licenses/by/4.0/). 